\title{
Do Underlying Risk Preferences explain Individuals' Cognitive Ability?* Evidence from a Sample of Pakistani Students
}

\author{
Mariam Raheem* and Ain ul Momina**
}

\begin{abstract}
Emerging research in empirical economics posits a question on the relation between underlying risk preferences and reflective cognitive ability. In an experimental setting, a preliminary sample of 260 participants undergo a series of incentivized choice experiments to elicit risk preferences and a Cognitive Reflection Test (CRT) to obtain estimates of their reflective ability. We sidestep potential biases by using a Fechner error specification along with a contextualized version of the utility function. Individuals who are more likely to avoid risky outcomes have significantly lower scores on the CRT. The analysis validates a prominent relationship spanning the economics and psychology literature and suggests a potential direction of causal inference for future research.
\end{abstract}

Keywords: Risk, cognitive reflective ability, behavioral economics, Pakistan.

JEL Classifications: C36, C91, D81, D90.

\section{Introduction and Literature Review}

Risk and time preferences are two distinct yet inseparable phenomena in the context of behavioral economics. Recent empirical work has focused on the relationship between underlying risk preferences and cognitive ability. Following on Andersson et al. (2016), we hypothesize that a significant relationship exists between underlying risk preferences and reflective cognitive ability. This hypothesis is tested in a controlled

\footnotetext{
* This experiment was conducted in collaboration with the Department of Economics at LUMS. We would like to express gratitude to Dr. Karrar Hussain (Assistant Professor, LUMS) for his valuable support and mentorship without which this work may not have been possible.

* Centre for Economic Research in Pakistan (CERP); Department of Economics, MGSHSS, Lahore University of Management Sciences, Pakistan; 19020199@lums.edu.pk

** Department of Community Medicine, King Edward Medical University, Lahore, Pakistan; ainmomina@gmail.com
} 
experimental setting with a sample of 260 university students. Each participant was asked to participate in a sequence of incentivized choice experiments and laboratory games to elicit risk preferences, followed by a Cognitive Reflection Test (CRT) to obtain estimates of their reflective ability. Our results find a significant relationship between these measures that feature prominently in the fields of economics and psychology.

While economists often interpret risk preferences as stable characteristics, experimental analyses have shown that they may vary conditional on the context, payoff - real or hypothetical - and even the target group. Recently a possible relationship between cognitive ability and an individual's attitudes towards risk have been explored. Almeida (2019) speculates on the important policy implications that stem from a possible link between the two: if cognitive ability affects attitudes in the face of uncertainty, and if ability is shaped by schooling, then targeted reforms in the education sector could eventually help individuals improve their investment behavior (Almeida, 2019). Similarly, in recent studies, Dohmen et al. (2018) present evidence that cognitive ability is related to risk-taking behavior. In a related study, Cueva et al. (2016) document that, on average, impulsive decisionmakers are more risk-averse than reflective ones.

Recent literature relating cognitive ability and behavior under risk looks at correlational links between the two. The relationships established in recent empirical analyses (Burks, Carpenter, Goette, \& Rustichini, 2009; Dohmen, Falk, Huffman, \& Sunde, 2010; Benjamin, Brown \& Shapiro, 2013) are often based on biased inferences. These biases emerge due to chance errors and a failure to acknowledge the discrepancies between individuals' actual and observed choices. Following Hey \& Orme (1994) our analysis accounts for this by making use of a CRRA utility function together with a contextualized version ${ }^{1}$ of the Fechner error specification (Wilcox, 2011).

For elicitation of risk attitudes, incentivized choice experiments are often used. Following the ideology initially put forth by Binswanger (1980), the experiments in our analysis involve real monetary payoffs, albeit small, to identify risk attitudes using the Multiple Price List model. The choice experiments were designed to be as simple as possible and follow the popular structure set out by Holt and Laury (2002) and Eckel and Grossman (2008). Individuals chose lotteries from a menu of alternative

\footnotetext{
${ }^{1}$ This contextualized version is based on the psychologically plausible notion that the subjective perception of each lottery's valuation in the pair differs depending on the context and domain in the analysis (See Wilcox (2011)).
} 
gambles with substantial financial stakes. ${ }^{2}$ Further, using individuals' switching points elicited from these choice experiments, along with a minimal set of structural assumptions, individual discount rates are estimated (Andreoni \& Sprenger, 2012).

Finally, individuals' ability is measured by way of the Cognitive Reflection Test (CRT). The use of the CRT as a measure of reflective ability ${ }^{3}$ and not just numerical reasoning is supported by the results of Campitelli and Gerrans (2014) who endorse rational thinking for both genders. Additionally, the CRT's assessment of the test taker's ability to ignore an often incorrect intuitive answer in favor of a contemplative right answer, warrants its use for this study (Frederick, 2005).

Our results suggest a negative association between risk aversion and reflective ability. These findings are robust to multiple specifications of the utility function as well as error structures. As will be seen, our results indicate that individuals who are more likely to avoid risky outcomes have significantly lower scores on the CRT, controlling for individual preferences and socio-demographic factors. While the methods employed address biases that can tamper with valid causal inferences in the relation being tested, this study serves as a step towards establishing the implicit connection between standard risk preferences and objective measures of reflective ability.

The remaining sections proceed as follows: Section 2 explains the methodology and experimental design. Section 3 outlines our econometric specification and estimation strategy while Section 4 presents the results and finally, section 5 concludes.

\section{Experimental Details}

\subsection{Overview}

The study was conducted at a university in Lahore, Pakistan over the duration of three weeks. The preliminary sample comprised 260 undergraduate students who took part in all segments of the experiment. Following this, the experiment continued with a series of incentivized laboratory games. There were two sessions for training and decision

\footnotetext{
${ }^{2}$ See Section 2.2; Appendix D

${ }^{3}$ Note that the measure of ability used throughout the text reflects a highly specific measure of cognitive ability. At no point do the authors claim that the CRT can be used to measure intelligence or holistic ability.
} 
making and two sessions for task completion. It was mandatory for participants to be physically present in the training sessions, where they were briefed about the tasks in detail. The training venues had a designated person in charge of the session accompanied by one or two assistants. For the sessions on training and decision making, participants were randomly assigned to 1 of 8 different venues. Details of the experimental design and tasks required by the participants are described in further detail in the subsequent sections.

\subsection{Experimental Design}

A set of questionnaires was provided to our sample of 260 individuals in eight different venues within the university campus. Each individual was randomly assigned to a venue and a group beforehand. Each participant received an email the night before the session informing them of the venue assigned to them. During the sessions, questionnaires asking them to record their personal demographics and Big 5 personality traits were also administered. Following this, the participants were asked to take part in different laboratory games which allowed the experimenters to predict behavioral tendencies, such as attitudes towards risk, cognitive reflective ability, self- and over-confidence. Only the effort/task allocation activity was conducted in a group, while the remaining experiments and surveys were conducted individually.

After cleaning the data and dropping individuals who demonstrated inconsistencies (e.g. incomplete tasks, preference reversals, or corner solutions), the main sample used for analysis consisted of 188 individuals. The reduction in sample size is explained in the coming subsections. Sections 2.2.1 to 2.2.3 elaborate this in further detail.

\subsubsection{Measures of Cognitive Reflective Ability}

To measure reflective ability, a Cognitive Reflection Test (CRT) consisting of three questions was presented to each subject. The premise of using this test as a measure of cognitive ability is supported by findings that it is a good predictor of performance based on the tendency to choose high expected value gambles, discounting, and framing effects (Frederick, 2005). The 3-item CRT is designed such that it tests an individual's ability to deliberate and "reflect" upon the first intuitive answer that comes to mind. Our analysis makes use of this particular measure of cognitive ability, which we refer to as cognitive reflective ability, not to be confused with intelligence, or holistic cognitive ability. 
Hence, the main analysis in this paper makes use of a combined measure of this CRT whereby each question is assigned 1 for a correct answer and 0 for an incorrect answer. Resultantly, the combined measure has values in the range of 0 to 3 with each question getting assigned a weight of $1 / 3$.

Table 2.1 - Summary Statistics for Results of the Administered CRT Test

\begin{tabular}{lccc}
\hline CRT results & Score (out of 3) & No. of Individuals & Percentage \\
\hline All 3 correct & 3 & 70 & $27 \%$ \\
At least 2 correct & 2 & 72 & $55 \%$ \\
At least 1 correct & 1 & 62 & $78 \%$ \\
No correct & 0 & 56 & $21 \%$ \\
\hline
\end{tabular}

Table 2.1 above shows that only 27 percent of the individuals were able to score perfectly in the CRT test, while 21 percent scored a zero. To further break this down with respect to each question, Table 2.2 shows the number of individuals who answered each question correctly, and presents them subsequently as a percentage of the entire sample to give a better idea of sample dynamics. A majority, 59 percent, was able to answer question 2 correctly, while question 1 was answered correctly by the least number of participants. This is also likely because of the more intuitive answer of "10 cents" which was the most common incorrect answer for question 1.

Table 2.2 - CRT Test Results: Breakdown with respect to each respective question.

\begin{tabular}{lcc}
\hline & \multicolumn{2}{c}{ Correct answers } \\
\cline { 2 - 3 } Question No. & Observations & \% of Individuals \\
\hline 1 & 127 & $49 \%$ \\
2 & 154 & $59 \%$ \\
3 & 135 & $52 \%$ \\
\hline
\end{tabular}

Similar results were seen when the same CRT was administered to students from selected universities, and performance statistics for 5 universities, inclusive of the selected university, are presented in Table 2.3. When asked the same three questions, it can be seen that only students from MIT were better performers, on average. This may possibly be biased due to the relatively smaller sample size. However, students in our sample are seen to have performance similar to these universities. 


\section{Table 2.3 - CRT performance from selected universities; ${ }^{4}$ Reproduced from Frederick (2005)}

\begin{tabular}{lcccccc}
\hline \multirow{2}{*}{ University } & Mean & \multicolumn{2}{c}{$\%$ of students scoring } & & Sample \\
& CRT score & $\mathbf{0}$ & $\mathbf{1}$ & $\mathbf{2}$ & $\mathbf{3}$ & Size \\
Sample university in Lahore & 1.60 & $27 \%$ & $28 \%$ & $24 \%$ & $22 \%$ & 260 \\
Massachusetts Institute of & 2.18 & $7 \%$ & $16 \%$ & $30 \%$ & $48 \%$ & 61 \\
Technology & & & & & & \\
Princeton University & 1.63 & $18 \%$ & $27 \%$ & $28 \%$ & $26 \%$ & 121 \\
Carnegie Mellon University & 1.51 & $25 \%$ & $25 \%$ & $25 \%$ & $25 \%$ & 746 \\
Harvard University & 1.43 & $20 \%$ & $37 \%$ & $24 \%$ & $20 \%$ & 51 \\
Overalla & 1.24 & $33 \%$ & $28 \%$ & $23 \%$ & $17 \%$ & 3428 \\
\hline
\end{tabular}

\subsubsection{Elicitation of Risk Preferences}

For the purposes of this paper, two risk elicitation tasks were used i.e. the Holt and Laury (HL) task, and the Eckel Grossman (EG) task. Both tasks make use of choices made by individual subjects taking part in the experiment based on simple choice tasks.

As expected, the data collected is prone to errors. To eliminate noise from the raw data, we drop participants who exhibit preference reversals, inconsistencies, or multiple switches. Additionally, in order to ensure corner solutions are not included, we run different specifications that exclude participants who switch at either the first or the last point. Since most of the data obtained from the HL task was not useful after collection and subsequent cleaning, for the final analysis, we mainly rely on the EG task for our inferences. The next sections include further details.

\section{i) Eckel-Grossman task}

The Eckel-Grossman (EG) task allows subjects to choose a single gamble; participants are asked to choose a gamble from a menu of six gambles. Each of the gambles, presented in Appendix D-2.1, has a high payoff and a low payoff, both with an equal likelihood. For instance, Gamble 1 has a certain payoff of Rs200. All subsequent gambles increase in both expected return and risk (standard deviation) moving from Gamble 1 to 5.5 The gambles are designed such that risk-averse subjects are likely to choose gambles with smaller variance. This method allows for

\footnotetext{
${ }^{4}$ See: Frederick (2005), Table 1 - "CRT Scores, by location"; Sample ulniversity scores are calculated from the data.

${ }^{5}$ Note: Gamble 5 and Gamble 6 have the same expected return but different standard deviation (Refer to Appendix D-2.1: Eckel-Grossman Method).
} 
parametric estimation for a coefficient of risk aversion ${ }^{6}$ (Charness et al., 2013). The task followed a simple design and takes only a few minutes to explain and implement successfully. Hence, in order for the two tasks to be comparable, the available data for EG task was modeled such that it was comparable to Holt and Laury data. ${ }^{7}$ Table 2.4 presents summary statistics for both, the simple "Overall" sample and the HL comparable data denoted by "Model".

Table 2.4 - Summary statistics for Eckel Grossman task

\begin{tabular}{lllllll}
\hline & \multicolumn{5}{c}{ Switching Points } \\
& Observations & Mean & Min & Max & Std. Dev. \\
\hline Overall & 252 & 3.37 & 0 & 6 & 1.94 \\
Model & 260 & 2.00 & 0 & 5 & 1.79 \\
\hline
\end{tabular}

The EG task required subjects to indicate their choice among six individual gambles. For this purpose, the EG data for decisions regarding the six gambles was converted into five implicit HL equivalent binary decisions following Dave et al. (2010). In doing so, an individual's risk aversion decreases down the group. For further analysis, this study makes use of the EG task as the primary instrument for risk elicitation as will be discussed.

\section{ii) Holt and Laury Task}

The HL task follows the format of a multiple price list, and allows researchers to measure attitudes towards risk. Since the methodology is simple and easily understood, this measure presents a more general phenomenon to explain risk preferences. Each participant is asked to choose a paired gamble from a menu of ten paired gambles. ${ }^{8}$ The two gambles for each decision are "stacked in rows", with gambles in the left and right columns labeled Option A and Option B, respectively (Charness et al., 2013). Participants then choose which gamble they prefer from each pair. Payoffs for each pair remain constant throughout the ten gambles. The probability associated with each payoff, however, varies; the probability of the high payoff increases when moving from row 1 to 10 . This implies that risk aversion decreases as the switching point increases. The switching point, for the purpose of this paper, is defined as the row where the participant switches over from Option A to Option B. This point

\footnotetext{
${ }^{6}$ Under certain assumptions, the chosen gamble then gives a reasonable estimate for the risk coefficient.

${ }^{7}$ Refer to Section 2.2.2 (ii) Holt and Laury task

${ }^{8}$ See: D-2.2: Holt and Laury Method in Appendix D.
} 
can then be used to estimate coefficients of risk aversion, conditional on assumptions regarding the functional form of utility (Bombardini \& Trebbi, 2012; Charness et al., 2013).

Although the HL task is easy to implement, it has certain drawbacks. The first and foremost being the ability for individuals to switch back and forth in their choices without any major repercussions. Individuals making decisions in the described manner will be referred to as "inconsistent" henceforth. The summary statistics for the Holt and Laury task are represented in Table 2.5.

Table 2.5 - Summary statistics for all specifications of the HL task

\begin{tabular}{lccccc}
\hline & \multicolumn{5}{c}{ Switching Points } \\
\cline { 2 - 6 } & Individuals & Mean & Min & Max & Std. Dev. \\
\hline Overall & 260 & 5.50 & 0 & 10 & 1.87 \\
Multiple & 142 & 5.47 & 0 & 10 & 1.76 \\
First & 249 & 5.75 & 1 & 10 & 1.50 \\
Last & 249 & 5.75 & 2 & 10 & 0.79 \\
\hline
\end{tabular}

The Holt and Laury specification included inconsistent switchers. A specification to restrict the data to strict preferences was used initially. Here, all inconsistent switchers were dropped and it was ensured that the data would only include strict preferences. Thus, the analysis in the subsequent section employs data from the sub-sample of strict preferences, or approximately 55 percent of the original sample. For robustness, different specifications and definitions of switching points were used. "Overall" represents the entire sample, however, these estimates are likely to be biased due to inconsistencies in switching between the gambles. The second specification "First" looks at the first switching point of the individual as the actual switching point, and the third, "last" looks at the last switching point as the actual switching point of a particular individual. The second and third specifications therefore give an idea about switching points at extremes. In both these cases, individuals who chose option A through all 10 gambles were dropped, and 96 percent of individuals in the actual sample remained, which explains the sub-sample of 249 individuals instead of 260 .

In accordance with the literature, the inclusion of subjects making inconsistent choices in experimental analysis are assumed to bias both the mean and the variance of individuals' risk attitudes to an extent that cannot be determined prior to the experimental analysis (Hirschauer, Musshoff, Maart-Noelck \& Gruener, 2013). Hence, inconsistent subjects are dropped 
from the main sample. Therefore, the summary statistics for the overall sample in Table 2.3 above, are excluded in any further analyses due to the presence of inconsistent switchers and the way missing values are treated in the data. The main sample, "Multiple", comprising 142 individuals, on average, had subjects switching between gambles 5 and 6 . The two extreme samples, for first and last switching points, show individuals switching around gamble 4 and gamble 9 respectively.

For both, the HL and EG tasks, the Constant Relative Risk Aversion (CRRA), exponential, and power utility functions are calculated respectively. However, as explained later, power utility was dropped during analysis. Summary statistics are presented in Appendix B: Utility Function Distribution Parametric Estimates.

\section{Methodology}

The experiment was conducted in two rounds. In Round 1, participants were required to fill out details about their demographic details and group dynamics.

The incentivized lottery questions as described previously were presented to 260 subjects. This series of questions allowed respondents to be ranked (into groups of ordinal levels) based on their certainty equivalent (CE). It is then assumed that individuals' preferences can be estimated using a particular utility function. This paper makes use of three particular functions, namely the Constant Relative Risk Aversion (CRRA), exponential, and the power utility function respectively. These functions obtain ranges for the coefficients of relative risk aversion. Under Expected Utility Theory (EUT), respondents who chose dominated options are said to have nonstandard preferences (gamble averse, gamble loving, negative time discounting) while those who chose dominating options are said to have standard preferences. In other words, standard preferences could be ranked, and the analysis, therefore, makes use of strictly standard preferences.

\subsection{Coding and Estimation:}

The data for individuals was coded with a unique identifier, "id", for ease. The variable "problem" indicates each consecutive rows. Individual switching points are represented as a binary variable "choices" whereby a value of 0 indicates that option A was chosen, and 1 indicates option B. "m1a", "m2a", " $\mathrm{m} 1 \mathrm{~b}$ ", and " $\mathrm{m} 2 \mathrm{~b}$ " represent the high and low payoffs for options A and B respectively. Lastly, "scale" and "wealth" 
represent the initial endowments and the factor that the final payoffs are scaled up with. (Note: In this case, both have been kept at 0.)

The model is formulated as a structural estimation approach as suggested by Harrison and Rutström (2008). The parameters of the model are simultaneously estimated in STATA using maximum likelihood techniques. The estimation is used to calculate estimates for the entire sample, with standard errors clustered for each group, and then separately for each individual to aid further analysis.

Following the three assumptions for functional forms of utility, the utility functions used are represented below, with " $\gamma$ " corresponding to the coefficient of relative risk aversion and " $\mathrm{x}$ " corresponding to wealth.

1. CRRA

$$
U(x)=\frac{x^{1-\gamma}}{1-\gamma}
$$

2. Exponential

$$
U(x)=1-e^{-\gamma x}
$$

3. Power

$$
U(x)=x^{\gamma}
$$

Individuals with $\gamma>0$ can be classified as risk-averse, $\gamma<0$ as risk loving and $\gamma=0$ as risk neutral. For the remainder of this paper, the focus lies on the concavity of the utility function, i.e. $\gamma>0$, as the focus, in particular, is on differing degrees of risk aversion only.

\subsection{Estimation Strategy:}

Maximum Likelihood Estimation (MLE) is used to first jointly estimate the parameter, $\gamma$, for the aggregated samples and then separately for individuals in the sample, respectively. ${ }^{9}$ Under the assumptions of EUT, , a standard CRRA utility function is used along with binary choice data over the two lotteries. First, joint estimation of the model as a whole is done. Then, in-sample forecasting is used to obtain estimates for each

\footnotetext{
${ }^{9}$ Note: The sample size is relatively small and may be prone to noise due to minor biases in students' answers.
} 
individual. Table 3.1 presents the obtained estimates and statistics for both, the sample and the individuals.

Table 3.1 - Joint Estimation results for all samples and all utility functions

\begin{tabular}{lccc}
\hline & \multicolumn{3}{c}{ Eckel and Grossman Task } \\
& $\boldsymbol{\gamma}_{\text {CRRA }}$ & $\boldsymbol{\gamma}_{\text {exponential }}$ & $\boldsymbol{\gamma}_{\text {power }}$ \\
\hline Model 10 & $0.758^{* * *}$ & $0.005^{* * *}$ & $0.192^{* * *}$ \\
(sample) & $(0.001)$ & $(0.000)$ & $(0.031)$ \\
Model 11 & $0.677^{* * *}$ & 0.012 & $0.169^{* *}$ \\
(calculated) & $(0.082)$ & $(0.012)$ & $(0.151)$ \\
Individuals & 248 & 248 & 248 \\
\hline
\end{tabular}

Robust standard errors in parentheses.

${ }^{* * *} \mathrm{p}<0.01,{ }^{* *} \mathrm{p}<0.05,{ }^{*} \mathrm{p}<0.1$

Table 3.2 then presents results for the Holt and Laury task only. Row 2 shows the average as calculated after obtaining the individual estimates. These sample and individual estimates are represented for the three utility functions specified in Section 3.1.

For further analyses, as discussed in Section 2 and as presented by Dave et al. (2010), the simplicity of the Eckel Grossman task ensures less noisy data despite lower predictive accuracy. Hence, for the preliminary analysis the answers to this task are used.

Table 3.2 - Joint (sample) and individual (calculated) estimates for the main sample

\begin{tabular}{lccc}
\hline & \multicolumn{3}{c}{ Holt and Laury Task } \\
\cline { 2 - 4 } & $\gamma_{\text {CRRA }}$ & $\gamma_{\text {exponential }}$ & $\gamma_{\text {power }}$ \\
\hline Overall & $0.728^{* * *}$ & $0.017^{* * *}$ & $0.645^{* * *}$ \\
(sample) & $(0.005)$ & $(0.000)$ & $(0.018)$ \\
Overall & $0.709^{* * *}$ & 0.072 & $0.8178^{* *}$ \\
(calculated) & $(0.1233)$ & $(0.2460)$ & $(0.3169)$ \\
Individuals & 260 & 260 & 260 \\
\hline
\end{tabular}

Robust standard errors in parentheses.

*** $\mathrm{p}<0.01,{ }^{* *} \mathrm{p}<0.05,{ }^{*} \mathrm{p}<0.1$

For the analysis in Section 4, the CRRA function is considered to be the parametrized utility function of interest, and the power utility function is excluded completely. Exclusion of the power utility function is justified

\footnotetext{
${ }^{10}$ Results as produced by the statistical package, STATA 13.0 .

${ }^{11}$ Averages and standard deviations calculated by making use of individual data.
} 
on the basis of an even smaller sample size. Additionally, during estimation, it requires more complex restrictions to ensure non-negativity, i.e., it violates the assumption of strict risk aversion.

While the experimenters in the original Holt and Laury experiment observed Increasing Relative Risk Aversion (IRRA), we assume strict risk aversion $(\gamma>0)$ for our sample, so EUT coupled with the CRRA function serves the purpose for our deterministic model. During estimation, we follow Harrison and Rutström (2008), and incorporate stochastic error stories in our maximum likelihood framework. The Fechner error specification $^{12}$ allows for an adjustment of potential errors that may arise when individuals reveal their risk preferences.

Previous experimental studies that introduce a "noise" parameter rely on different kinds of error specification models. Since EUT is least affected by the selection of the error specification, and based on our analysis of stochastic errors in Appendix E, our analysis predominantly relies on the Fechner error specification (Drichoutis \& Lusk, 2014; Wilcox, 2011; Wilcox, 2008; Hey \& Orme, 1994). ${ }^{13}$

After obtaining the estimates through MLE, an OLS regression of the following form is run to determine the relationship between the variables, where $y_{i}$ represents the dependent variable and $x_{i}$ represents the dependent variable for each individual $i$.

$$
y_{i}=\beta x_{i}+u_{i}
$$

The dependent variable is the measure of cognitive reflective ability, and the independent variable is the parametric estimate of risk aversion $(\gamma)$ for each respective individual.

\subsubsection{Controls}

While the discussion has explained our main variables of interest, additional data was also collected during the experimental drive. This included certain demographic variables, personality traits as measured by the Big 5 personality test, and data to measure confidence. Variables that are likely to affect a participant's performance on the CRT are included as controls.

\footnotetext{
12 See Hey \& Orme (1994).

${ }^{13}$ Refer to Appendix E - Functional Form of Utility and Stochastic Errors
} 


\section{Overconfidence}

Participants answer a series of general knowledge questions (See Appendix D-3: General knowledge test for measurement of overconfidence). Following their response to each factual question, they are asked for a subjective assessment of the accuracy of their answer. The residual $\left(\mu_{i}\right)$ from a regression of each participant's qualitative assessment $\left(Y_{i}\right)$ on a fourth-order polynomial of the participant's accuracy $\left(X_{i}\right)$ is overprecision. This over-precision is then used as a measure of overconfidence.

$$
Y_{i}=\beta_{1} X_{i}+\beta_{2} X_{i}^{2}+\beta_{3} X_{i}^{3}+\beta_{4} X_{i}^{4}+\mu_{i}
$$

The reliance on over-precision as a measure of overconfidence instead of all 3 conflated components as described by Moore and Healy (2008), is discussed in further detail in Appendix F.

\section{Results}

The main analysis of this paper relies upon the Eckel Grossman method for elicitation of risk preferences; and the CRRA utility function. Broadly speaking, the results suggest that as the parameter " $\gamma$ " increases, a person's level of risk aversion increases. When looking at this in relation to CRT results, as the level of risk aversion increases, an individual's CRT score decreases. This is suggestive of the fact that better performing individuals are prone to risk-seeking behavior and low performance is indicative of risk-averse behavior.

This is likely to hold because measures of cognitive reflective ability as measured by the CRT are suggestive of decision-making abilities. Lower scores imply poor decision making and higher scores imply better decisionmaking abilities. If this holds, then the results are in line with what one can expect intuitively. Examples from different contexts and domains show that negative correlation between reflective ability and risk aversion is frequently encountered in economic, psychological, and even sociological literature.

The results for the OLS estimation give us a direction for the relationship that the paper set out to test. The more risk-prone an individual is, the higher is their performance on the CRT. The main analysis is drawn from the specification in column (5) of Table 4. 


\section{Table 4 - Regression Results using Ordinary Least Squares}

\begin{tabular}{|c|c|c|c|c|c|c|}
\hline \multirow[t]{2}{*}{ Variables } & (1) & (2) & (3) & (4) & (5) & (6) \\
\hline & \multicolumn{6}{|c|}{ Dep. Variable $=$ Total CRT Score } \\
\hline \multirow{2}{*}{$\gamma_{\text {CRRA }}$} & -1.312 & -1.364 & $-1.646^{*}$ & $-2.147^{* *}$ & $-2.021^{*}$ & $-1.637^{*}$ \\
\hline & $(0.75)$ & $(0.76)$ & $(0.76)$ & $(0.79)$ & $(0.82)$ & $(0.77)$ \\
\hline \multirow[t]{2}{*}{ Age } & & -0.008 & 0.006 & 0.033 & 0.065 & 0.035 \\
\hline & & $(0.05)$ & $(0.06)$ & $(0.06)$ & $(0.07)$ & $(0.06)$ \\
\hline Gender & & -0.219 & -0.166 & -0.268 & -0.251 & -0.16 \\
\hline$($ Female $=0)$ & & $(0.2)$ & $(0.21)$ & $(0.22)$ & $(0.29)$ & $(0.27)$ \\
\hline On-campus Job & & & -0.134 & -0.176 & -0.166 & \\
\hline$(\mathrm{No}=0)$ & & & $(0.156)$ & $(0.167)$ & $(0.193)$ & -0.04685 \\
\hline \multirow[t]{2}{*}{ Study Hours } & & & -0.134 & -0.176 & -0.166 & \\
\hline & & & $(0.156)$ & $(0.167)$ & $(0.193)$ & -0.04685 \\
\hline Class Time & & & -0.134 & -0.176 & -0.166 & $=04685$ \\
\hline Preference & & & $(0.156)$ & $(0.167)$ & $(0.193)$ & -0.04685 \\
\hline \multirow[t]{2}{*}{ Language } & & & & 0.006 & & 0.009 \\
\hline & & & & $(0.021)$ & & $(0.023)$ \\
\hline \multirow[t]{2}{*}{ Province } & & & & -0.009 & & -1.272 \\
\hline & & & & $(0.078)$ & & $(0.083)$ \\
\hline Overconfidence & & & & & $-0.196^{* * *}$ & $-0.208^{* * *}$ \\
\hline A & & & & & $(0.069)$ & $(0.076)$ \\
\hline \multirow[t]{2}{*}{ Overconfidence B } & & & & & -0.196 & -0.315 \\
\hline & & & & & $(0.232)$ & $(0.244)$ \\
\hline \multirow[t]{2}{*}{ Overconfidence C } & & & & & 0.32 & 0.29 \\
\hline & & & & & $(0.133)$ & $(0.158)$ \\
\hline \multirow{2}{*}{ Constant } & $2.606^{* * *}$ & $2.882^{*}$ & $3.046^{*}$ & 1.54 & 1.815 & 2.392 \\
\hline & $(0.55)$ & (1.17) & $(1.33)$ & $(2.09)$ & $(1.97)$ & $(1.39)$ \\
\hline Observations & 142 & 142 & 138 & 125 & 99 & 112 \\
\hline $\mathrm{R}^{2}$ & 0.023 & 0.033 & 0.076 & 0.102 & 0.123 & 0.101 \\
\hline
\end{tabular}

Robust standard errors in parentheses.

${ }^{* * *} \mathrm{p}<0.01,{ }^{* *} \mathrm{p}<0.05,{ }^{*} \mathrm{p}<0.1$

To check for robustness, additional regressions are run using different sub-samples and slightly changing the assumptions. The results involving the estimates constructed using the Holt and Laury method of risk elicitation are included in Appendix C. As can be seen, the direction of the relationship stays the same despite changing the sample or the utility function's specification used. ${ }^{14}$ Under the assumption of monotonic preferences, the subjects prefer the lottery up to a certain level of the safe option, and then switch to preferring the safe option in all subsequent rows of the choice table (Dohmen et al., 2010).

Hence, both choice tasks for the main sample being used are representative of monotonic preferences. Existing literature has often

\footnotetext{
${ }^{14}$ Only main sample and specification results are included with and without controls. See: Appendix C.
} 
focused more on the EG task because it is easier to understand and comprehend relative to the HL task, however, dropping multiple switchers in our main sample seems to make our data comparable to past studies. To further validate this, the relationship between the two variables of interest is indeed seen to hold through a series of robustness checks.

Looking at demographic variables, the coefficient on gender suggests that compared with females, males are seen to have bad performance on the CRT. The relationship holds throughout all the regression specifications. Age is negatively associated, potentially due to cognitive decline or due to increased errors pertaining to the nature of the questions and spontaneity bias. In the analysis, "overconfidence" is included to control for inconsistencies in students' performance in the Cognitive Reflection Tests. ${ }^{15,16}$ Category A of overconfidence includes five general knowledge questions and is seen to have a statistically significant result. That is, higher overconfidence is associated with a 0.197 unit decline in the subject's performance on the CRT. The result is plausible due to the design of CRT questions as mentioned earlier in the paper. Moreover, while other variables are not statistically significant, the direction of the relationship can still be established. In light of this view, category $B$ is seen to have a positive relation with CRT score. This category involves questions pertaining to the labor force and inflation rates, and it can be assumed that individuals who answer these questions correctly generally have knowledge in this particular area, and are therefore, more confident about their answers. The final

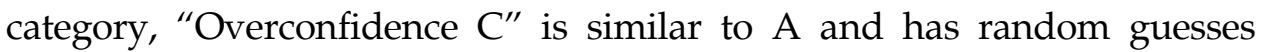
regarding the population of the university. It is prone to chance error and biases in the answers leading to a negative relation with CRT score.

As a final check, additional preference characteristics were also included. Students who had an on-campus job were likely to get higher scores possibly because they reflected on their answer before finalizing it. Classroom time preferences, and study hours show declining scores. Classroom time preferences is a categorical variable which takes on higher values if classes later in the day were preferred. The way the variable is coded explains why individuals who prefer evening classes over morning classes may score lower on tests of ability.

\footnotetext{
${ }^{15}$ The measure of overconfidence is constructed following Ortoleva \& Snowberg (2015)'s methodology.

${ }^{16}$ Participants are asked factual questions followed by a qualitative assessment of their accuracy. A regression of this assessment on a fourth-order polynomial of the participant's accuracy gives overprecision. Then, the first principal component of these measures is used to measure overconfidence (Chapman et al., 2019).
} 
Despite the large standard errors, it can be noted that other determinants of performance are relevant as they help capture more of the variation in this data. The OLS estimates as shown in Appendix C despite presenting much smaller covariates do not reach conventional levels of statistical significance. However, they are in the same direction and help further strengthen the direction of the relationship. The relationship, therefore, is strongly negative and serves the purpose of this study.

\section{Conclusion}

This paper set out to test whether underlying risk preferences and a highly specific measure of cognitive ability, specifically reflective ability, of an individual are related. Based on the results, the main findings suggest that people with lower reflective ability are significantly more risk-averse, whereas, those with higher reflective ability (as measured by CRT performance) are more risk-loving. While the analysis does present significant results, it does not overlook noise in self-reports, as the main sample used throughout has 142 individuals and may not overlook the biases. However, from a behavioral context, this study still leads us to conclude that there is, in fact, a robust and significant relationship between a person's preferences towards risk and their cognitive ability.

The two variables of interest, risk preferences and cognitive reflective ability, are considered to be two primitives of standard decision theory. The relationship between the two seems general and intuitive and is likely to hold over an array of contexts and domains. Thinking of high cognitive ability as a measure of an individual's problem-solving abilities, the person would be likely to take risks and improvise if they face any negative consequence, to overcome it.

In financial settings, a few studies on cognitive ability, financial literacy and risky behavior show that cognitive ability improves quality of decision making such that the decision maker's ability to recognize when risk-taking is beneficial (in financial terms) improves. Christelis, Jappelli and Padula (2010), for example, present a correlation between high cognitive ability and increased risk-taking behavior in financial settings. Grinblatt, et al. (2011) also show that investors with higher IQ have a tendency to hold portfolios that are less risky and have higher returns. This may also shed light on better decision making on the part of the investors.

Noori (2016) documents evidence from Pakistan suggesting that participants who score lower on the CRT also exhibit risk aversion in the 
domain of gain. Hence, the results presented in Section 4 are in line with recent research in the field. Similarly, Frisell, Pawitan, and Långström (2012) found a negative relationship between IQ score and convicted felons in Sweden. Their results suggest that people tend to immerse in socially acceptable behaviors and take fewer risks pertaining to crimes. Bellanti and Bierman (2000) presented that low cognitive ability was linked with pro-social skill deficits. Likewise, the findings presented by Frisell et. al (2012) can be generalized to reinforce the idea that people with higher cognitive ability may be willing to indulge in risky behavior while those with lower cognitive ability may conform to societal norms and have cautious tendencies.

In terms of policy implications, if higher cognitive ability is related to an increased willingness to take risks, this could affect the design of interventions aimed at improving an individual's future economic outcomes. If an individual's tendency to exhibit risk-aversion affects their performance on the CRT, important implications can be derived. Intuitively, a person who steers clear of an uncertain situation is also likely to face problems in simple problem solving tasks. Interventions that target managerial skills and decision making abilities can help build their ability to think, plan, and ultimately act more responsibly. Our results, therefore, are similar to prominent research in the field. However, as discussed by prominent researchers, the results are reflective of correlations due to certain limitations such as the relatively small sample size, and the use of a single measure of ability among other things (Dohmen et al., 2010; Harrison \& Rutström, 2008; Charness et al., 2019).

Although causality is difficult to establish as in most behavioral contexts, this analysis leads us to conclude that there is, in fact, a robust and significant relationship between some highly specific metrics of a person's ability and their preferences towards risk. This study therefore, adds to the limited bodies of literature on a highly important subject and serves as a stepping stone for future researchers to test more nuanced approaches that validate the relation between individuals risk preferences and their cognitive ability. 


\section{References}

Almeida, S. (2019). Do as I Do, Not as I Say: Incentivization and the Relationship Between Cognitive Ability and Risk Aversion. Revista Brasileira de Economia, 73(4), 413-434.

Andersson, O., Holm, H. J., Tyran, J. R., \& Wengström, E. (2016). Risk aversion relates to cognitive ability: Preferences or Noise? Journal of the European Economic Association, 14(5), 1129-1154.

Andreoni, J., \& Sprenger, C. (2012). Estimating time preferences from convex budgets. American Economic Review, 102(7), 3333-56.

Augenblick, N., Niederle, M., \& Sprenger, C. (2015). Working over time: Dynamic inconsistency in real effort tasks. The Quarterly Journal of Economics, 130(3), 1067-1115.

Baum, C.F., Schaffer, M. E., \& Stillman, S. (2007). Enhanced routines for instrumental variables/generalized method of moments estimation and testing. The Stata Journal, 7(4), 465-506.

Bazerman, M.H., Tenbrunsel, A.E., \& Wade-Benzoni, K. (1998). Negotiating with yourself and losing: Making decisions with competing internal preferences. Academy of Management Review, 23(2), 225-241.

Becker, G.M., DeGroot, M.H., \& Marschak, J. (1963). An experimental study of some stochastic models for wagers. Behavioral Science, 8(3), 199-202.

Beier, M. E., \& Ackerman, P.L. (2001). Current-events knowledge in adults: An investigation of age, intelligence, and nonability determinants. Psychology and aging, 16(4), 615.

Bellanti, C.J., \& Bierman, K. L. (2000). Disentangling the impact of low cognitive ability and inattention on social behavior and peer relationships. Journal of Clinical Child Psychology, 29(1), 66-75.

Benjamin, D. J., Brown, S. A., \& Shapiro, J. M. (2013). Who is 'behavioral'? Cognitive ability and anomalous preferences. Journal of the European Economic Association, 11(6), 1231-1255. 
Bombardini, M., \& Trebbi, F. (2012). Risk aversion and expected utility theory: an experiment with large and small stakes. Journal of the European Economic Association, 10(6), 1348-1399.

Bub, K.L., McCartney, K., \& Willett, J.B. (2007). Behavior problem trajectories and first-grade cognitive ability and achievement skills: A latent growth curve analysis. Journal of Educational Psychology, 99(3), 653.

Burks, S. V., Carpenter, J. P., Goette, L., \& Rustichini, A. (2009). Cognitive skills affect economic preferences, strategic behavior, and job attachment. Proceedings of the National Academy of Sciences, 106(19), 7745-7750.

Campitelli, G., \& Gerrans, P. (2014). Does the cognitive reflection test measure cognitive reflection? A mathematical modeling approach. Memory E Cognition, 42(3), 434-447.

Chapman, J., Dean, M., Ortoleva, P., Princeton, N. C., Snowberg, E., \& Camerer, C. (2019). Econographics.

Charness, G., Garcia, T., Offerman, T., \& Villeval, M. C. (2019). Do Measures of Risk Attitude in the Laboratory Predict Behavior under Risk in and outside of the Laboratory? (No. 12395). IZA Discussion Papers.

Charness, G., Gneezy, U., \& Imas, A. (2013). Experimental methods: Eliciting risk preferences. Journal of Economic Behavior $\mathcal{E}$ Organization, 87, 43-51.

Christelis, D., Jappelli, T., \& Padula, M. (2010). Cognitive abilities and portfolio choice. European Economic Review, 54(1), 18-38.

Dave, C., Eckel, C. C., Johnson, C. A., \& Rojas, C. (2010). Eliciting risk preferences: When is simple better? Journal of Risk and Uncertainty, 41(3), 219-243.

Dohmen, T., Falk, A., Huffman, D., \& Sunde, U. (2010). Are risk aversion and impatience related to cognitive ability? American Economic Review, 100(3), 1238-60.

Drichoutis, A. C., \& Koundouri, P. (2012). Estimating risk attitudes in conventional and artefactual lab experiments: The importance of the underlying assumptions. Economics Discussion Paper, 2012-19. 
Drichoutis, A. C., \& Lusk, J. L. (2014). Judging statistical models of individual decision making under risk using in-and out-of-sample criteria. PloS one, 9(7).

Fechner, G. T., Howes, D. H., \& Boring, E. G. (1966). Elements of psychophysics, 1. New York: Holt, Rinehart and Winston.

Finlay, K., \& Magnusson, L. M. (2009). Implementing weak-instrument robust tests for a general class of instrumental-variables models. The Stata Journal, 9(3), 398-421.

Frederick, S. (2005). Cognitive reflection and decision making. Journal of Economic perspectives, 19(4), 25-42.

Frisell, T., Pawitan, Y., \& Långström, N. (2012). Is the association between general cognitive ability and violent crime caused by family-level confounders? PloS one, 7(7).

Gillen, B., Snowberg, E., \& Yariv, L. (2019). Experimenting with measurement error: Techniques with applications to the caltech cohort study. Journal of Political Economy, 127(4), 1826-1863.

Grinblatt, Mark, Matti Keloharju and Juhani Linnainmaa. IQ and Stock Market Participation. The Journal of Finance 66.6 (2011): 2121-2164.

Gollier, C. (2001). Should we beware of the precautionary principle?. Economic Policy, 16(33), 302-327.

Gollier, C. (2001). Wealth inequality and asset pricing. The Review of Economic Studies, 68(1), 181-203.

Halevy, Y. (2008). Strotz meets Allais: Diminishing impatience and the certainty effect. American Economic Review, 98(3), 1145-62.

Harless, D. W., \& Camerer, C. F. (1994). The predictive utility of generalized expected utility theories. Econometrica: Journal of the Econometric Society, 1251-1289.

Harrison, G., \& Rutström, E. (2008). Risk aversion in the laboratory. Research in Experimental Economics, 12, 41-196.

Hey, J. D., \& Orme, C. D. (1994). Investigating Generalisations of Expected Utility Theory using Experimental Data. Econometrica, 62(6). 
Hirschauer, N., Musshoff, O., Maart-Noelck, S., \& Gruener, S. (2013). Eliciting risk attitudes - how to avoid mean and variance bias in Holt-and-Laury lotteries. Applied Economics Letters, 21(1), 35-38.

Holt, C. A., \& Laury, S. K. (2002). Risk aversion and incentive effects. American economic review, 92(5), 1644-1655.

Hussain, K. (n.d.) Fickle Groups: An Empirical Assessment of Time Preferences Using Experimental Data.

Jamison, J., \& Wegener, J. (2010). Multiple selves in intertemporal choice. Journal of Economic Psychology, 31(5), 832-839.

Jamison, J., Karlan, D., \& Zinman, J. (2012). Measuring risk and time preferences and their connections with behavior. Handbook of Experimental Economics, 2.

Kahneman, D., \& Tversky, A. (1979). Prospect Theory: An Analysis of Decision under Risk. Econometrica, 47(2), 263-291. doi:10.2307/1914185

Loomes, G., \& Sugden, R. (1995). Incorporating a stochastic element into decision theories. European Economic Review, 39(3-4), 641-648.

Luce, R. D. (1959). Individual choice behavior.

Monterosso, J., Ehrman, R., Napier, K. L., O'Brien, C. P., \& Childress, A. R. (2001). Three decision-making tasks in cocaine-dependent patients: Do they measure the same construct? Addiction, 96(12), 1825-1837.

Oechssler, J., Roider, A., \& Schmitz, P. W. (2009). Cognitive abilities and behavioral biases. Journal of Economic Behavior E Organization, 72(1), 147-152.

Ortoleva, P., \& Snowberg, E. (2015). Overconfidence in political behavior. American Economic Review, 105(2), 504-35.

Ponti, G., \& Rodriguez-Lara, I. (2015). Social preferences and cognitive reflection: evidence from a dictator game experiment. Frontiers in behavioral neuroscience, 9, 146. 
Steel, P. (2007). The nature of procrastination: A meta-analytic and theoretical review of quintessential self-regulatory failure. Psychological bulletin, 133(1), 65.

Tanaka, T., Camerer, C. F., \& Nguyen, Q. (2010). Risk and time preferences: Linking experimental and household survey data from Vietnam. American Economic Review, 100(1), 557-71.

Thaler, R. H., \& Shefrin, H.M. (1981). An economic theory of selfcontrol. Journal of Political Economy, 89(2), 392-406.

Wilcox, N. T. (2008). Stochastic models for binary discrete choice under risk: A critical primer and econometric comparison. Risk aversion in experiments, 12, 197-292.

Wilcox, N. T. (2011). Stochastically more risk averse: A contextual theory of stochastic discrete choice under risk. Journal of Econometrics, 162(1), 89-104. 


\section{Appendices}

\section{Appendix A - Data Specific Tables ${ }^{17}$}

\begin{tabular}{|c|c|}
\hline Variable & Description \\
\hline id_old & Original identification code \\
\hline iq1 & CRT question 1 \\
\hline iq2 & CRT question 2 \\
\hline iq3 & CRT question 3 \\
\hline Totaliq & Cumulative score in CRT \\
\hline group_beta1 & Present bias for the group \\
\hline group_delta1 & Discount factor for the group \\
\hline Betai & Present bias for the individual \\
\hline Deltai & Discount factor for the individual \\
\hline Gender & Female $=0$ \\
\hline Studyhrs & Average hours of study outside class \\
\hline Job & No on-campus job $=0$ \\
\hline class_timepref & Morning $=1$, Afternoon $=2$, Noon $=3$, Evening $=4$ \\
\hline Familyincome & Monthly household income \\
\hline overconfidence_A & Based on general knowledge questions \\
\hline overconfidence_B & Based on UNIVERSITY related questions \\
\hline overconfidence_C & Based on unemployment/inflation questions \\
\hline Confidence & Based on all questions \\
\hline hl_sp & Holt-Laury Switching Point \\
\hline eg_sp & Eckel-Grossman Switching Point \\
\hline eg_crra & Eckel-Grossman parameter estimates \\
\hline eg_exp & Eckel-Grossman parameter estimates \\
\hline hl_all_crra & $\begin{array}{l}\text { Holt-Laury parameter estimates - Sample with multiple } \\
\text { switchers }\end{array}$ \\
\hline hl_m_crra & $\begin{array}{l}\text { Holt-Laury parameter estimates - Sample without multiple } \\
\text { switchers }\end{array}$ \\
\hline hl_all_exp & $\begin{array}{l}\text { Holt-Laury parameter estimates - Sample with multiple } \\
\text { switchers }\end{array}$ \\
\hline hl_m_exp & $\begin{array}{l}\text { Holt-Laury parameter estimates - Sample without multiple } \\
\text { switchers }\end{array}$ \\
\hline
\end{tabular}

A-1: Description of Variables.

${ }^{17}$ All tables in this appendix are derived from the raw data using Stata 13.0 


\begin{tabular}{|c|c|c|c|c|c|}
\hline Variable & Observations & Mean & Std Dev & Min & $\operatorname{Max}$ \\
\hline id_old & 244 & 154.619 & 91.580 & 1 & 308 \\
\hline iq1 & 244 & 0.496 & 0.501 & 0 & 1 \\
\hline iq2 & 244 & 0.594 & 0.492 & 0 & 1 \\
\hline iq3 & 244 & 0.525 & 0.500 & 0 & 1 \\
\hline Totaliq & 244 & 1.615 & 1.122 & 0 & 3 \\
\hline group_beta1 & 244 & 1.021 & 1.180 & 0.019 & 10.873 \\
\hline group_delta1 & 244 & 0.886 & 0.147 & -0.450 & 0.994 \\
\hline Betai & 244 & 1.188 & 1.568 & 0.027 & 15.091 \\
\hline Deltai & 244 & 0.895 & 0.074 & 0.661 & 1.000 \\
\hline Gender & 244 & 0.357 & 0.480 & 0 & 1 \\
\hline Studyhrs & 240 & 3.059 & 1.975 & 0.5 & 20 \\
\hline Job & 240 & 0.063 & 0.243 & 0 & 1 \\
\hline class_timepref & 243 & 2.029 & 0.820 & 1 & 4 \\
\hline Familyincome & 196 & 162,225 & 241,382 & 10,000 & $2,000,000$ \\
\hline overconfidence_A & 214 & 0.000 & 1.276 & -3.308 & 2.963 \\
\hline overconfidence_B & 220 & 0.000 & 1.391 & -1.252 & 19.726 \\
\hline overconfidence_C & 215 & 0.000 & 1.424 & -3.763 & 3.826 \\
\hline Confidence & 207 & 0.000 & 1.814 & -5.817 & 4.472 \\
\hline EG & 236 & 3.331 & 1.922 & 0 & 6 \\
\hline hl_sp & 244 & 5.541 & 1.895 & 0 & 10 \\
\hline eg_sp & 244 & 2.119 & 1.777 & 0 & 5 \\
\hline eg_crra & 232 & 0.678 & 0.082 & 0.593 & 0.768 \\
\hline eg_exp & 232 & 0.012 & 0.012 & 0.003 & 0.037 \\
\hline hl_all_crra & 244 & 0.732 & 0.112 & 0.485 & 1.055 \\
\hline hl_m_crra & 136 & 0.714 & 0.121 & 0.485 & 1.055 \\
\hline hl_all_exp & 244 & 0.040 & 0.093 & 0.014 & 0.490 \\
\hline hl_m_exp & 136 & 0.075 & 0.252 & 0.014 & 1.181 \\
\hline
\end{tabular}

A-2: Summary Statistics. 


\section{Appendix B: Utility Function Parametric Estimates}

\section{B-1.1: Holt and Laury Method}

\begin{tabular}{|c|c|c|c|c|}
\hline & $\gamma_{\text {CRRA }}$ & & $\mu$ & $\Sigma$ \\
\hline \multirow[t]{2}{*}{ Multiple } & 0.6995 & $(.0092)$ & $\begin{array}{l}0.0670 \\
(0.0152)\end{array}$ & $\begin{array}{l}0.4821 \\
(0.0019)\end{array}$ \\
\hline & $\gamma_{\text {expo }}$ & & $\mu$ & $\Sigma$ \\
\hline \multirow[t]{2}{*}{ Multiple } & 0.0165 & $(0.0001)$ & $0.0783 \quad(0.0123)$ & $0.4178 \quad(0.0009)$ \\
\hline & $\gamma_{\text {power }}$ & & $\mu$ & $\Sigma$ \\
\hline Multiple & 0.7507 & $(0.0211)$ & - & - \\
\hline
\end{tabular}

\section{B-1.2: Eckel Grossman Method}

\begin{tabular}{|c|c|c|c|}
\hline & $\gamma_{\text {CRRA }}$ & $\mu$ & $\boldsymbol{\sigma}$ \\
\hline \multirow[t]{2}{*}{ Model } & $0.7584 \quad(0.0007)$ & $0.0618 \quad(0.0073)$ & $0.2705 \quad(0.0017)$ \\
\hline & $\gamma_{\text {expo }}$ & $\boldsymbol{\mu}$ & $\boldsymbol{\sigma}$ \\
\hline \multirow[t]{2}{*}{ Model } & $0.0055 \quad(0.0000)$ & $0.0027 \quad(0.0002)$ & $0.0087 \quad(0.0001)$ \\
\hline & $\gamma_{\text {power }}$ & $\mu$ & $\Sigma$ \\
\hline Model & $0.1919 \quad(0.0311)$ & $\# \mathrm{~N} / \mathrm{A}$ & $\# \mathrm{~N} / \mathrm{A}$ \\
\hline
\end{tabular}




\section{Appendix C: Additional Regression Outputs}

\section{C-1: OLS Results using the Eckel Grossman Method}

\begin{tabular}{|c|c|c|c|c|c|c|}
\hline \multirow[t]{2}{*}{ Variables } & $(1)$ & $(2)$ & (3) & $(4)$ & $(5)$ & $(6)$ \\
\hline & \multicolumn{6}{|c|}{ Dep. Variable $=$ Total CRT Score } \\
\hline \multirow{2}{*}{$\gamma_{C R R A}$} & 0.221 & 0.335 & 0.250 & 0.169 & 0.561 & 0.688 \\
\hline & $(0.851)$ & $(0.858)$ & $(0.893)$ & $(0.969)$ & $(1.012)$ & $(1.139)$ \\
\hline \multirow[t]{2}{*}{ Age } & & -0.047 & -0.044 & -0.022 & -0.073 & -0.049 \\
\hline & & $(0.042)$ & $(0.045)$ & $(0.047)$ & $(0.048)$ & $(0.051)$ \\
\hline \multirow[t]{2}{*}{ Gender $($ Female $=0)$} & & -0.172 & -0.134 & -0.176 & -0.166 & $-0.221^{*}$ \\
\hline & & $(0.148)$ & $(0.156)$ & $(0.167)$ & $(0.193)$ & $(0.212)$ \\
\hline \multirow[t]{2}{*}{ On-campus Job $(\mathrm{No}=0)$} & & & -0.277 & -0.207 & -0.268 & -0.141 \\
\hline & & & $(0.284)$ & $(0.319)$ & $(0.283)$ & $(0.329)$ \\
\hline \multirow{2}{*}{ Study Hours } & & & -0.025 & -0.006 & -0.031 & -0.013 \\
\hline & & & $(0.036)$ & $(0.036)$ & $(0.039)$ & $(0.038)$ \\
\hline \multirow[t]{2}{*}{ Class Time Preference } & & & -0.064 & -0.055 & -0.103 & -0.113 \\
\hline & & & $(0.088)$ & $(0.099)$ & $(0.091)$ & $(0.105)$ \\
\hline \multirow[t]{2}{*}{ Language } & & & & 0.006 & & 0.009 \\
\hline & & & & $(0.021)$ & & $(0.023)$ \\
\hline \multirow[t]{2}{*}{ Province } & & & & -0.009 & & -1.272 \\
\hline & & & & $(0.078)$ & & $(0.083)$ \\
\hline \multirow[t]{3}{*}{ Overconfidence A } & & & & & - & - \\
\hline & & & & & $0.196^{* * *}$ & $0.208^{* * *}$ \\
\hline & & & & & $(0.069)$ & $(0.076)$ \\
\hline \multirow[t]{2}{*}{ Overconfidence B } & & & & & -0.196 & -0.315 \\
\hline & & & & & $(0.232)$ & $(0.244)$ \\
\hline \multirow[t]{2}{*}{ Overconfidence C } & & & & & $0.159^{* * *}$ & $0.145^{*}$ \\
\hline & & & & & $(0.071)$ & $(0.079)$ \\
\hline \multirow[t]{2}{*}{ Constant } & $1.479^{* *}$ & $2.413^{* *}$ & $2.615^{* *}$ & $2.638^{* *}$ & $3.119^{* *}$ & $3.148^{* *}$ \\
\hline & $(0.578)$ & $(0.994)$ & $(1.113)$ & $(1.310)$ & $(1.266)$ & $(1.586)$ \\
\hline Observations & 248 & 248 & 240 & 211 & 201 & 211 \\
\hline $\mathrm{R}^{2}$ & 0.000 & 0.012 & 0.019 & 0.019 & 0.0763 & 0.0768 \\
\hline
\end{tabular}

Robust standard errors in parentheses.

*** $\mathrm{p}<0.01,{ }^{* *} \mathrm{p}<0.05,{ }^{*} \mathrm{p}<0.1$ 


\section{Appendix D: Questionnaires}

\section{D-1: Cognitive Reflection Test to measure Ability}

\section{Questions}

1. A bat and a ball cost $\$ 1.10$ in total. The bat costs $\$ 1.00$ more than the ball. How much does the ball cost?

2. If it takes 5 machines 5 minutes to make 5 widgets, how long would it take 100 machines to make 100 widgets?

3. In a lake, there is a patch of lily pads. Every day, the patch doubles in size. If it takes 48 days for the patch to cover the entire lake, how long would it take for the patch to cover half of the lake?

\section{D-2: Elicitation of Risk Preferences}

\begin{tabular}{lllll}
\hline & Roll & Payoff & Chances & Mark only one \\
\hline Gamble 1 & Low & Rs. 200 & $50 \%$ & \\
& High & Rs. 200 & $50 \%$ & \\
Gamble 2 & Low & Rs. 160 & $50 \%$ & \\
Gamble 3 & High & Rs. 280 & $50 \%$ \\
& Low & Rs. 120 & $50 \%$ \\
Gamble 4 & High & Rs. 360 & $50 \%$ \\
& Low & Rs. 80 & $50 \%$ \\
Gamble 5 & High & Rs. 440 & $50 \%$ \\
& Low & Rs. 40 & $50 \%$ \\
Gamble 6 6 & High & Rs. 520 & $50 \%$ \\
& Low & Rs. 0 & $50 \%$ & \\
& High & Rs. 600 & $50 \%$ & \\
\hline
\end{tabular}

D-2.1: Eckel Grossman Method. 


\begin{tabular}{lllll}
\hline Choice & \multicolumn{1}{c}{ Gamble A } & Choice & \multicolumn{2}{c}{ Gamble B } \\
\hline \multirow{2}{*}{1} & $1 / 10$ of & $9 / 10$ of & $1 / 10$ of & $9 / 10$ of \\
& Rs. 200 & Rs. 120 & Rs. 400 & Rs. 20 \\
& $2 / 10$ of & $8 / 10$ of & $2 / 10$ of & $8 / 10$ of \\
3 & Rs. 200 & Rs. 120 & Rs. 400 & Rs. 20 \\
& $3 / 10$ of & $7 / 10$ of & $3 / 10$ of & $7 / 10$ of \\
4 & Rs. 200 & Rs. 120 & Rs. 400 & Rs. 20 \\
\multirow{4}{*}{5} & $4 / 10$ of & $6 / 10$ of & $4 / 10$ of & $6 / 10$ of \\
& Rs. 200 & Rs. 120 & Rs. 400 & Rs. 20 \\
6 & $5 / 10$ of & $5 / 10$ of & $5 / 10$ of & $5 / 10$ of \\
& Rs. 200 & Rs. 120 & Rs. 400 & Rs. 20 \\
7 & $6 / 10$ of & $4 / 10$ of & $6 / 10$ of & $4 / 10$ of \\
& Rs. 200 & Rs. 120 & Rs. 400 & Rs. 20 \\
8 & $7 / 10$ of & $3 / 10$ of & $7 / 10$ of & $3 / 10$ of \\
& Rs. 200 & Rs. 120 & Rs. 400 & Rs. 20 \\
9 & $8 / 10$ of & $2 / 10$ of & $8 / 10$ of & $2 / 10$ of \\
& Rs. 200 & Rs. 120 & Rs. 400 & Rs. 20 \\
\multirow{2}{*}{10} & $9 / 10$ of & $1 / 10$ of & $9 / 10$ of & $1 / 10$ of \\
& Rs. 200 & Rs. 120 & Rs. 400 & Rs. 20 \\
& $10 / 10$ of & $0 / 10$ of & $10 / 10$ of & $0 / 10$ of \\
\hline
\end{tabular}

D-2.2: Holt and Laury Method. 


\section{D-3: General knowledge test for measurement of overconfidence}

\section{Questionnaire}

1. In what year was the telephone invented? Even if you are not sure, please give us your best guess.

2. How confident are you of your answer to this question? (scale of 1-6)

1. No confidence at all

2. Not very confident

3. Somewhat unconfident

4. Somewhat confident

5. Very confident

6. Certain

3. As a different way of answering the previous question, what do you think the percent chance is that your best guess, entered above, is within 25 years of the actual answer?

4. What is the population of Spain, in millions? Even if you are not sure, please give us your best guess.

5 . How confident are you of your answer to this question?

1. No confidence at all

2. Not very confident

3. Somewhat unconfident

4. Somewhat confident

5. Very confident

6. Certain

6. As a different way of answering the previous question, what do you think the percent chance is that your best guess, entered above, is within 15 million of the actual answer?

7. In what year was the playwright William Shakespeare born? Even if you are not sure, please give us your best guess.

8. How confident are you of your answer to this question?

1. No confidence at all

2. Not very confident

3. Somewhat unconfident

4. Somewhat confident

5. Very confident

6. Certain 
9. As a different way of answering the previous question, what do you think the percent chance is that your best guess, entered above, is within 50 years of the actual answer?

10. What percent of the UNIVERSITY students lives in hostels? Even if you are not sure, please give us your best guess.

11. How confident are you of your answer to this question?

1. No confidence at all

2. Not very confident

3. Somewhat unconfident

4. Somewhat confident

5. Very confident

6. Certain

12. As a different way of answering the previous question, what do you think the percent chance is that your best guess, entered above, is within 5 percent of the actual answer?

13. What percent of the UNIVERSITY students are female? Even if you are not sure, please give us your best guess.

14. How confident are you of your answer to this question?

1. No confidence at all

2. Not very confident

3. Somewhat unconfident

4. Somewhat confident

5. Very confident

6. Certain

15. As a different way of answering the previous question, what do you think the percent chance is that your best guess, entered above, is within 5 percent of the actual answer? $\%$

16. According to the World Bank's World Development Indicator (WDI), since 1990 the most armed forces personnel (\% of total labor force) the Pakistan economy has had in a year is $2.39 \%$. The least in a year has been $1.48 \%$. Over the same period, the Pakistan economy has had an average of $1.84 \%$ a year. 
What is your best guess about the percentage of armed forces in the total labor force in the last year?

17. Over the past year, I think the percentage has overall
a) Increased a lot
b) Increased a bit

18. How confident are you of your answer to this question?

1. No confidence at all

2. Not very confident

3. Somewhat unconfident

4. Somewhat confident

5. Very confident

6. Certain

19. The inflation rate is the annual percentage change in prices for basic goods like food, clothing, housing, and energy. According to the World Bank's World Development Indicator (WDI), since 1960 in Pakistan it has ranged from a high of $26.6 \%$ (a $26.6 \%$ increase in prices over the previous year) to a low of $-0.51 \%$ (a $0.51 \%$ decline in prices over the previous year).

What is your best guess about the inflation rate in Pakistan today?

20. Do you think prices went up or down?
a) Up
b) Down

21. How confident are you of your answer to this question?

1. No confidence at all

2. Not very confident

3. Somewhat unconfident

4. Somewhat confident

5. Very confident

6. Certain

22. According to the World Bank's World Development Indicator (WDI), since 1990 the most armed forces personnel (\% of total labor force) the Pakistan economy has had in a year is $2.39 \%$. The least in a year has been $1.48 \%$. Over the same period, the Pakistan economy has had an average of $1.84 \%$ a year.

What is your best guess about the percentage of armed forces in the total labor force in the next year? 
23. I think the percentage will
a) Increase a lot
b) Increase a bit

23. What is the percentage do you think it will be in next coming year?

24. How confident are you of your answer to this question?

1. No confidence at all

2. Not very confident

3. Somewhat unconfident4. Somewhat confident5. Very confident6. Certain

25. The inflation rate is the annual percentage change in prices for basic goods like food, clothing, housing, and energy. According to the World Bank's World Development Indicator (WDI), since 1960 in Pakistan it has ranged from a high of $26.6 \%$ (a $26.6 \%$ increase in prices over the previous year) to a low of $-0.51 \%$ (a $0.51 \%$ decline in prices over the previous year).

What do you expect the inflation rate to be a year from now?

26. Do you think prices went up or down?
a) Up
b) Down

27. What percent do you expect prices to go up or down?

28. How confident are you of your answer to this question?

1. No confidence at all

2. Not very confident

3. Somewhat unconfident

4. Somewhat confident

5 . Very confident

6. Certain 


\section{Appendix E - Functional Form of Utility and Stochastic Errors}

The paper explored risk preferences of students using choice experiments and games in a laboratory setting. Experimental details along with methodology are mentioned in detail in Sections 2 and 3. As discussed, we used the Eckel Grossman method to conduct our analysis. This section elaborates upon the theoretical and empirical reasoning behind our choice of CRRA as the main functional form for an individual's utility and the introduction of a structural noise parameter, widely known as the Fechner error.

\section{E-1. Functional Form of Utility}

An analysis of anomalies in behavioral tendencies often points towards risk averse behavior on the individual's level. Based on our discussion in this paper, we rely on different functional forms of utility to measure an individual's Relative Risk Aversion (RRA). Based on the responses collected from a sample of undergraduate students, Figure E-1.1 shows the distribution function of individual switching points.

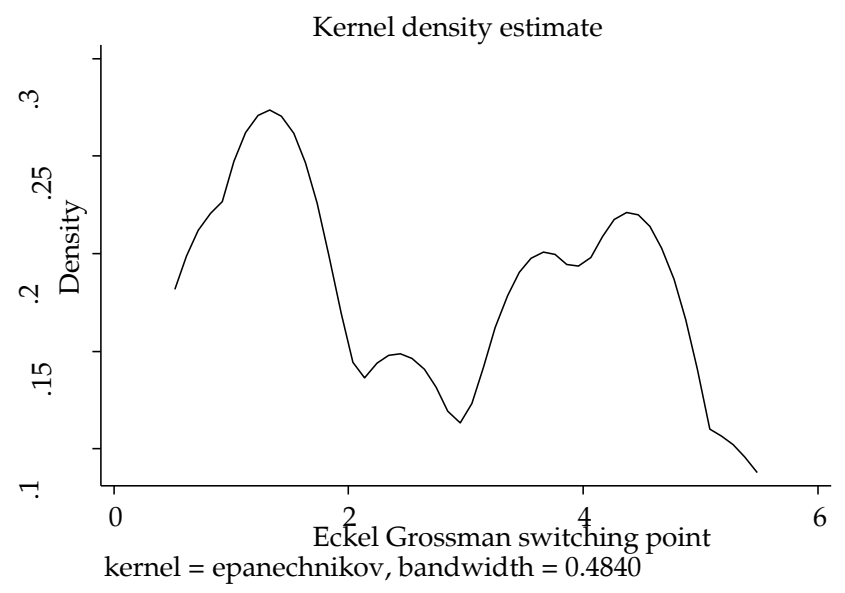

\section{Figure E-1.1: Distribution of switching points using the Eckel Grossman method}

The parameter of risk aversion in this analysis, $\gamma$, is estimated for each individual separately, using maximum likelihood estimation (MLE) in STATA. The individual estimates are mapped onto three different utility functions. Figure E-1.2 represents the distribution of individual parametric estimates using each of the three utility functions. Panel (a) represents the 
CRRA function, $U(x)=\frac{x^{1-\gamma}}{1-\gamma}$, (b) represents the exponential function, $U(x)=1-e^{-\gamma x}$, and (c) represents the power function, $U(x)=x^{\gamma}$.

While the CRRA function is frequently chosen in empirical evaluations owing to its tractability, Gollier (2001) presented empirical evidence, questioning its relevance in estimation procedures. Hence, based on this skepticism, and the discussion on our estimation strategy in Section 3, we map our individual estimates onto the specified utility functions.

Figure E-1.2: Distribution of estimated parameters using different utility functions

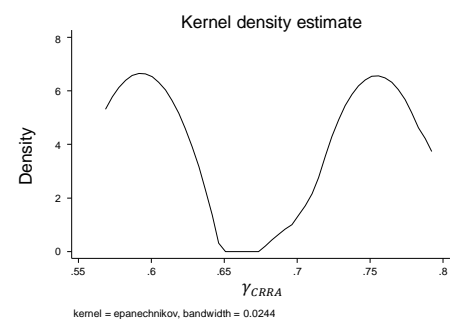

(a) $\gamma_{C R R A}$

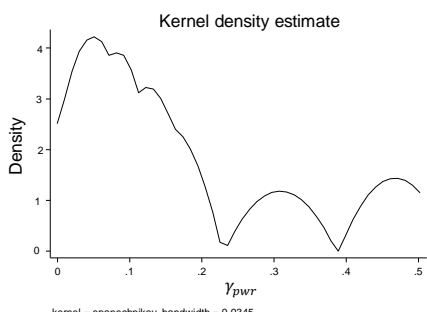

(c) $\gamma_{p w r}$

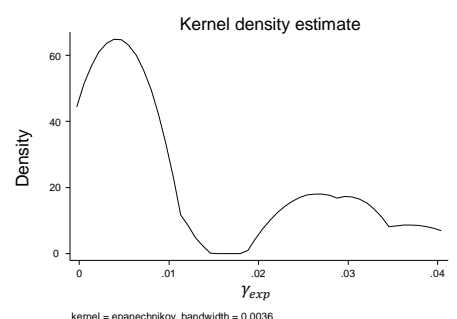

(b) $\gamma_{\text {exp }}$

Our theoretical reasoning coupled with the distributions shown in Figure E-1.2, it is evident that individual choices are mapped onto the CRRA function most closely, and hence, it forms the basis of our analysis.

\section{E-2. Stochastic Errors}

Following Harrison and Rutström (2008), once the utility function is specified, our structural model is further enhanced by incorporating a structural noise parameter, $\mu$. 
Wilcox (2007) presents a comprehensive review of different stochastic identifying restrictions from theoretical and empirical literature. He shows evidence that while adding stochastic errors in structural models can undoubtedly strengthen the estimation, it is also sensitive to the choice of error specification models. For our experimental analysis, we rely on two such error specifications. The first model, popularized by Holt and Laury (2002), in their original experiment on risk aversion, was initially proposed by Luce (1959). The second is accredited to Fechner (1860) and has been used extensively in emerging bodies of literature that look at experimental elicitation of risk aversion (Hey and Orme, 1994; Becker, DeGroot and Marschak, 1963).

While our analysis relies solely on the Fechner error specification, there is a need to understand the importance of the different structures of the noise parameter. In the deterministic Expected Utility Theory (EUT) model, Expected Utility (EU) is calculated for each estimate of $\gamma$. However, an increasing number of empirical studies rely on some kind of stochastic specification in the EUT model (See: See Harless \& Camerer, 1994; Loomes \& Sugden, 1995; Hey and Orme, 1994).

For our stochastic model, we introduce a latent preference index, $\nabla E U$, which varies with the choice of error specification. In EUT, this index is a simple difference between expected utilities of the pairwise lotteries: $\nabla E U=E U_{R}-E U_{L}$.

However, in both stochastic models discussed above, the latent preference index takes the form of a ratio instead of a simple difference. The indices under each respective specification are shown below ${ }^{18}$.

\section{i. Luce specification}

$$
\nabla E U=\frac{E U_{R}^{1 / \mu}}{E U_{R}^{1 / \mu}+E U_{L}^{1 / \mu}}
$$

\section{ii. Fechner Specification}

$$
\nabla E U=\frac{E U_{R}-E U_{L}}{\mu}
$$

\footnotetext{
${ }^{18}$ Estimates throughout the analysis follow the Fechner error specification.
} 
The Luce Specification assumes strict utility, while the Fechner Specification assumes strong utility. Our estimations rely predominantly on the Fechner error specification over the Luce specification (Hey and Orme, 1994; Holt and Laury, 2002). For more detailed reasoning, Wilcox (2008), uses data from the original HL task to highlight how it is imperative to exercise caution with stochastic identifying restrictions. 


\section{Appendix F: Measurement of Overconfidence}

Overconfidence comprises 3 often overlapping components (Moore \& Healy, 2008). Each of these components and their construction is defined below.

\section{a. Over-precision}

Following Ortoleva and Snowberg (2015), we focus on overprecision as our measure of overconfidence. It serves as evidence that participants practice imperfect information processing.

- Participants are asked factual questions. (E.g. What year was the telephone invented in?)

- After each factual question, the participant is asked for a qualitative assessment of the accuracy of their answer. ${ }^{19}$

The residual from a regression of this measure on a fourth-order polynomial of the participant's accuracy gives over-precision.

$$
Y_{i}=\beta_{1} X_{i}+\beta_{2} X_{i}^{2}+\beta_{3} X_{i}^{3}+\beta_{4} X_{i}^{4}+\mu_{i}
$$

Using one question from our questionnaire, we construct an example for individual $\mathrm{i}$,

\begin{tabular}{lll}
\hline Q1 & What year was the telephone invented in? & 1820 \\
Q2 & How confident are you about your answer? \\
(On a scale of 1-6, in order of decreasing confidence) & 4 \\
Q3 $\quad \begin{array}{l}\text { What do you think the \% chance is that your best guess is within } \\
25 \text { years of the actual answer? }\end{array}$ & 70 \\
\hline \multicolumn{2}{c}{ Correct answer $=1876$} \\
$\begin{array}{l}\text { Here, } \quad Y_{i}=\text { Subjective assessment of accuracy, } \\
X_{i}=\text { Actual answer - Participant's guess }(\text { answer to Q1) }=1876-\mathrm{Q} 1\end{array}$ \\
\hline
\end{tabular}

b. Over-estimation

Over-estimation $=$ No. of correct questions (perceived) - No. of correct questions (actual)

19 Observed overconfidence is commonly measured as the difference between mean subjective probability and proportion correct. 


\section{c. Over-placement}

Over-placement $=$ Perceived percentile of accuracy - Actual percentile of accuracy

Our measure of overconfidence relies on over-precision. This is precisely because over-precision and over-placement refer to the same factual quantity denoted by the participant's guess (referred to as Q1 in equation 2 above). Hence, when incorporating both, a need may arise to rule out spurious correlations due to correlated measurement error, a modification of the Obviously Related Instrumental Variables (ORIV) technique is often used (Chapman et al., 2018). 